\title{
INTEGRATION OF AUTOMATED DATA COLLECTION TECHNOLOGIES FOR REAL-TIME FIELD MATERIALS MANAGEMENT
}

\author{
Carlos H. Caldas, David G. Torrent, and Carl T. Haas \\ University of Texas at Austin \\ caldas@mail.utexas.edu.
}

\begin{abstract}
This paper describes a research study that is investigating data and technology requirements for the implementation of integrated real-time materials management on construction job sites. Specifically, the research aims (1) to formalize methods for accurate and timely materials tracking and (2) to define data integration needs between sensing technologies, materials management, and project control systems. The first phase of this study focused on materials locating technologies. Preliminary results from field trials conducted as part of the first phase of this project are presented.
\end{abstract}

Keywords: materials management, information technology, sensing, computer integrated construction

\section{INTRODUCTION}

Materials management, the process for planning and controlling all the necessary efforts to ensure that the right quality and quantity of materials are specified in a timely manner, obtained at reasonable cost, and used when needed [1], plays a major role in the construction industry. Materials management stands also for an essential project's control tool that when merged with engineering tries to reach both cost objectives and project needs [2]. In a typical construction project, materials account for $40-50 \%$ of its total cost. According to the 1997 U.S. Economic Census, the materials, components, supplies, and their management services for residential and industrial buildings, heavy construction, and infrastructure projects cost $\$ 124$ billions [3]. Materials management is also recognized as one of the industry's best practices by both the Construction Industry Institute (CII) and the European Construction Institute (ECI).

While materials management has been largely analyzed, its materials handling procedures on construction job sites, known as field materials management, remain almost unexploited. Contractors' planning effort in materials handling operations is extremely limited [4]. According to a CII study, materials' availability on construction job sites increases 6\% craft labor productivity in industrial projects, while the implementation of computerized support systems provides an additional gain between 4 and $6 \%$ [5]. Measurement of inefficiencies related to on-site materials handling operations confirms the potential for improving materials management on construction job sites.

Current field materials management processes are error prone and significantly decrease productivity. Locating and identifying materials on construction job sites consume excessive amounts of working time and labor effort, negatively acting on the construction success indicators of safety, schedule, and cost. In a study developed by O'Brien, the time spent on handling materials and preparatory operations by electrical workers was as much as $42 \%$, while devoting only $32 \%$ of their working time to productive tasks [4]. Bell and Stukhart stated that foremen lost $20 \%$ of their working time hunting for resources, while leaving the crews unsupervised and hence cutting productivity down [6]. According to the same authors, the availability of materials to begin an activity affects craft labor productivity by decreasing the number of repetitive site trips, and increasing the associated amount of time spent. On power plant construction sites, Borcherding observed that $27.7 \%$ of the craft worker's time was idle or nonproductive due to the unavailability of the correct materials and tools at the right time [7]. Significant competitive advantages would come through new technology devices to automatically control and update materials' information and status on construction job sites. For instance, automatic, reliable, and instant location of the on-site components belonging to critical activities would result in a confident and timely planning of the execution of those activities, and therefore minimize the risks of incurring project delays.

A recent Construction Industry Institute (CII) study identified field materials management as the area that company managements thought had both the greatest potential for improvement and the greatest positive development impact on engineering construction work processes [8]. According to $82 \%$ of the surveyed construction organizations, field materials management practices would be significantly improved by the introduction of technology, while $85 \%$ of those organizations agreed that technology devices would have a clear and positive impact 
within those practices. The knowledge of accurate and timely-identified construction materials is important for project success.

New technology and sensing devices can greatly enhance field materials management. Precise tracking, finding, and distributing of the correct materials at the right time would highly increase craft labor productivity, reduce labor idle-time and the number of repetitive site trips, and hence improve safety performance. Additionally, the overall number of work disruptions due to material unavailability would be reduced, creating a clear and positive benefit to cost ratio within the construction industry that would accelerate the deployment and implementation of new technology and sensing devices.

\section{BACKGROUND AND SIGNIFICANCE OF FIELD MATERIALS MANAGEMENT}

Manufacturing materials management has been extensively studied and successfully applied for decades. Inventory management, materialsrequirements-planning, and just-in-time delivery are the standard techniques for different demand environments, which are usually characterized by their levels of continuity, uniformity and dependency [9]. Within manufacturing, these demand characteristics are the most influential factors in determining the adequacy of a particular formal approach to materials management.

Materials management within construction resembles that of manufacturing only at a conceptual level [9]. Objectives, inputs, activities, and outputs are some of the conceptual parallelisms between manufacturing and construction materials management. However, unique and dynamic characteristics of construction environments, in conjunction with inaccurate or incomplete project data input, cause a lack of systematic methods to fulfill construction materials management principles and objectives.

Materials management needs to be understood as an integrated construction management process among all project stages. The harmonization and coordination of materials by the adequate methods and tools is necessary for business planning, preliminary design, final design, procurement, vendor control, construction, and project closeout. During the business planning phase, a materials manager is usually designated to report directly to the project manager, and a materials focus is clearly set in the project's mission statement. In the preliminary design phase, managers define materials' basic specifications while trying to minimize the design effort. As the final design goes on, the project team uses the generated information to prepare drawings and detailed specifications for materials' procurement. In the procurement phase, those specifications and long term factors, such as maintenance and operational costs, determine the best value for the price of each procured item. During vendor control, materials managers focus on avoiding changes in the specifications of the ordered materials, and on controlling their fabrication and delivery status. While constructing, the main focus is placed on field operations, with the goal of tracking, finding, and distributing the right material at the correct location at the precise time. Finally, the project closeout disposes of the surplus materials, while an analysis of the employed system generates future improvements and suggestions.

Successful approaches to manage construction materials possess intrinsic qualities and characteristics. Early planning, top management support and site training programs established early in the project are some of the basic attributes for a correct materials policy [10]. Additionally, the implementation of interconnected communication mechanisms among the different construction players is a condition for an effective management of construction materials. The presence of communication channels among the owner, the contractor, project managers, and the job site strengthen the correct flow of materials' information in a precise sequence.

The existence of a materials management system enhances this interconnectivity by sharing a common database, therefore eliminating redundant input while minimizing data storage. Its use further increases data accuracy, productivity and data-flow, and enables potential access to materials' real-time information. However, management systems need to be populated with the appropriate data.

Recent research initiatives explored the use of new technologies and sensing devices to collect materials' status on construction job sites in a timely manner. An early approach by Jaselskis et al. proposed radio frequency identification devices (RFID) for tracking high valued materials on construction job sites [11]. In a study implemented by Cheng and Chen, barcodes and geographic information systems (GIS) were the two basic components of an automated schedule monitoring system to control the erection of prefabricated concrete components [12]. Chen and Wong developed an incentive reward barcodeenabled program that encouraged on-site workers to decrease avoidable wastes [13]. Akinci et al. proposed radio frequency identification solutions for tracking precast concrete elements during their construction lifecycle, while keeping record of their as built information [14]. NIST conducts a research for establishing standards to support identification and tracking of construction components by means of different sensing technologies, such as barcodes, radio frequency identification devices, and global positioning systems (GPS) [15]. Finally, Stone et al. merged laser detection and ranging (LADAR's) with barcode technology in order to read the materials' identification labels at maximum distances between 30 and 40 meters [16]. 
Success from these research projects has opened the doors of automated data collection (ADC) technologies to manage materials on construction job sites. Combined with the latest versions in portable computers and wireless communications, ADC technologies may create the data stream for materials to move efficiently on construction job sites, substantially modifying current field materials management.

\section{AUTOMATED DATA COLLECTION (ADC) TECHNOLOGIES FOR FIELD MATERIALS MANAGEMENT}

ADC devices are continuously evolving and becoming common in industries such as manufacturing, logistics, and health care. Standard and off-the-shelf automated data collectors can be of great convenience on construction job sites, supporting automatic access to reliable real-time information of on-site materials.

\subsection{Barcode technology}

Barcode labels represent a read-only identifying technology extensively applied in manufacturing since 1970's. Barcode technology encloses the knowledge for encoding, printing, scanning, decoding, and verifying the symbols contained in labels. Electro-optical barcode scanners illuminate and read a symbol by measuring the reflected light's waveform; then, the measured signal is digitalized. This sensing system enables the identification of labeled items, requiring a clear line-of-sight between label and reader in maximum distances of inches.

While traditional one-dimensional codes have small storage capacities, two-dimensional encoding systems have highly increased them. Twodimensional stacked and matrix codes act as a database, assuring a complete visualization of the labeled item by means of the stored information. Correction and error detection decoding techniques are a fundamental part of these expanded systems.

Even though barcode's low-costs and off-the-shelf solutions can accelerate its deployment within the construction industry, the need for a clear line-ofsight with short read ranges and the finite lifetime of the labels under harsh environments limit its applications on construction job sites.

\subsection{Contact memory buttons}

Contact memory buttons stands for a read/write technology for use in extreme environments. The hermetically sealed buttons are capable to resist severe temperatures, shocks, vibrations, radiations, and maintenance in aggressive solvents and salty waters. However, the technology requires direct contact between the memory device and a button link connected to a portable computer to read or update the information in the button. Maximum commercial storage capacities range up to $8 \mathrm{Mb}$.

Contact memory buttons are a growing technology with multiple applications in severe environments, such as that of the U.S. Department of Defense, and those of the oil, railroads and manufacturing industries.

\subsection{Radio Frequency Identification Devices (RFID)}

RFID is a wireless read/write identification system that emerged in the 80's. RFID provides for sending and receiving data via radio signals with non-contact and non-line-of-sight between components, even under hostile environments. An RFID system is composed by three components, antennas or metal coils, transceivers, and transponders (tags). Usually antenna and transceiver are mounted together to become a reader. When a tag's antenna detects a radio signal from a receiver, it replies back to the receiver sending the encoded information.

Transponders are classified as either active or passive. On the one hand, passive tags operate with the energy of the signal transmitted by the reader and usually are read-only devices, acting for identification purposes. On the other hand, active tags are powered by an internal battery and are $\mathrm{read} /$ write. The trade off between them is that active tags have larger memories (up to a few $\mathrm{Mb}$ ) and longer read ranges (up to a maximum of 100 feet), while passive tags are lighter, smaller and more economical.

The promises of growth of the technology that would enhance performances and reduce costs, together with its non-contact and non-line of sight nature, would make RFID an ideal technology for locating and tracking materials on construction job sites.

\subsection{Smart labels}

Smart labels stand for a simplified and inexpensive version of RFID tags. Working with similar radio frequency principles, smart labels operate with a silicon microprocessor that connects printed carbonink electrodes (instead of the tag's metal coil) on the reverse of a paper label.

Although the resulting price (usually less than \$0.5) and the physical flexibility of the tags may be attractive for the construction industry, their extremely limited read ranges and low memory keep them away from construction job sites.

\subsection{Global Positioning System (GPS)}

GPS is an outdoor satellite-based worldwide radionavigation system formed by a constellation of 24 satellites, ground control stations, and end users. GPS uses triangulation from these satellites in order to determine a three dimensional position. To triangulate, a GPS receiver needs to compute the 
distances to at least four different satellites at any given time. Distances to the receiver are computed measuring the travel time of radio signals from each one of these four satellites. Atmosphere conditions and satellites' location above the receiver influence the resulting position and its accuracy.

By default, any computed position has an intrinsic maximum error of 45 feet (raw data). However, differential GPS (DGPS) decreases the error of the raw data using a fixed receiver whose position must be previously known. Ground base stations, coastguard beacons, WAAS, and OmniSTAR receivers reduce the error to less than 10 feet, while real-time kinematic GPS (RTK GPS) minimizes the position's error to less than one centimeter in a few miles radius around a separate base station, having a trade off in highly increased costs.

GPS is an established location technology that offers a wide range of off-the-shelf solutions in both hardware and software. Although GPS applications are not uncommon in construction practices, such as positioning of equipment and surveying, its potential to improve the management of materials on construction job sites remains unexplored.

\subsection{Laser scanners}

A laser scanner is a range finder with a spherical sensor device that measures distances to the surrounding objects. A diode laser emits a pulse of light that, when colliding with an object, partially reflects back to the range finder. A direct comparison of the phases of the emitted and returned signal determines the distance to the object. The output signal is in the form of consecutive scan lines. The effective depth of field of a laser scanner normally ranges between 3 and 300 feet.

Even though laser scanners would deliver highly accurate visual information of a construction scene, the tremendous computational effort to transform the raw visual data into meaningful information, the inability of the technology to see through objects, and the relatively slow scans have focused this technology for solving other civil engineering problems.

\subsection{Laser Detection And Ranging (LADAR)}

LADARs are another variant of laser range finders. A photomultiplier processes the returned photons of an emitted light pulse and simultaneously obtains the time-off-flight range distances to the impacted objects. The output signal is a visualization of the objects in front of the LADAR in terms of distances.

When compared with laser scanners, LADARs have a poor horizontal and vertical coverage, and a short depth of field. However, LADARs have lower costs and provide for close real-time visual information.

At the present time, the unavoidable presence of obstacles in dynamic construction environments, the need for post-processing the raw visual data, and the experimenting stage of the technology slow down the introduction of LADARs on construction job sites.

\subsection{Webcams}

Webcams can provide real-time visual information of construction job sites. Even though their application can be clearly profitable in some construction applications due to commercial availability and low costs, the high post-processing efforts of the collected data to identify, track and locate materials make their use impractical for tasks that require some expertise.

\subsection{Portable computers}

Mobile and wearable computers offer a convenient way to collect, access, and store real-time data on construction job sites. Personnel digital assistants, handheld computers, rugged laptop computers, and touch-screen computers come usually equipped with wireless communication hardware and software, becoming effective tools to overcome traditional, time consuming, and unreliable paper work. However, portable computers as automated data collectors rely on human-data entry. Other potential technologies discussed in this paper are better suit for the data gathering process.

\section{CASE STUDY}

FIATECH (Fully Integrated and Automated Technology), an industry consortium focused on research, development, and deployment of technologies within capital projects and facilities, has an ongoing project, called Smart Chips, that aims to investigate the use of sensing technologies in construction job sites. One of the pilot studies conducted by the Smart Chips project team is presented here.

\subsection{Project description}

The project applied GPS technology to improve the process of locating pipe spools in lay down yards of large industrial projects. FIATECH, the Smart Chips project, Kellogg Brown and Root (KBR), British Petroleum (BP), Trimble, Data Scan, Geo Spatial Innovations (GSI), and the University of Texas at Austin were the key project participants.

\subsection{Objectives}

The goals of this study were to quantify the potential benefits derived from the integration of GPS within materials locating processes and to evaluate its technical feasibility, assessing in its limitations and providing recommendations for further 
improvements. Lay down yards were the preferred scenario for measuring those potential benefits.

\subsection{Technology used}

To achieve these objectives, the selected locating technologies were integrated with current materials management systems. Accurate and smooth integration of field materials management processes, new technology devices, database management systems, and data transformation/transmission were the backbone of this study.

\subsubsection{GPS System}

Trimble's GPS Pathfinder Power determined its own location at any given time. The GPS reader was a combination of differential GPS (DGPS) receiver and antenna. Position was defined in terms of three coordinates (X, Y, and Z). The backpack mounted device (Figure 1) enabled a real-time sub-meter accuracy using OmniSTAR DGPS correction.

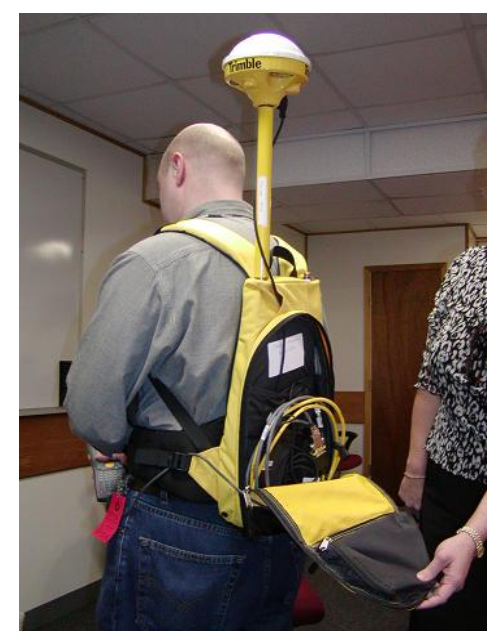

Figure 1. GPS antenna and receiver

\subsubsection{Handheld device and software}

The handheld computer PDT 8100 was a rugged data-collection device. The computer was wired to the GPS receiver in order to enable the collection of measured positions. PDT 8100 incorporated key data entry option and sealed joints to withstand construction environment's demands. A $1 / 4$ VGA display touchable screen allowed the end user to interact with software packages.

GSI's Pocket Collector software had two main functions. First, it operated as the interface between the end user and the GPS receiver. Second, Pocket Collector integrated the GPS position-based functions of navigation, tracking, timing, and mapping (Figure 2).

\subsection{Preliminary results}

Thus far, the research team has accomplished the first two steps of the project. In the first step, the team selected the appropriate technology devices and integrated them with current locating methods. In the second step, the team performed a field trial to verify the feasibility of the GPS technology to locate materials.

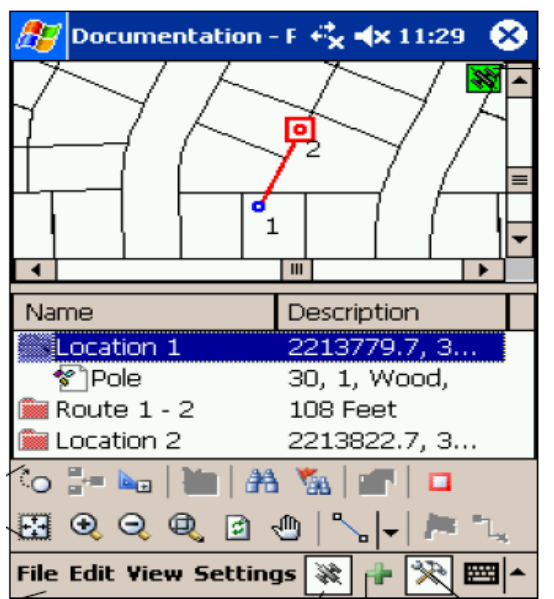

Figure 2. Positions of both targeted pipe spool and user could be visualized

\subsection{Field trial}

The field trial was designed to analyze the technical feasibility of the GPS technology for locating materials. The field trial consisted in finding 20 components that had been previously tagged with a barcode label, and their positions recorded in the handheld computer. The GPS navigation and mapping functions were the basis of the user search. Once the user learned how to manage the handheld device and software, all the items were successfully identified and located. The sub-meter accuracy was required to locate a particular item in crowded areas (Figure 3).

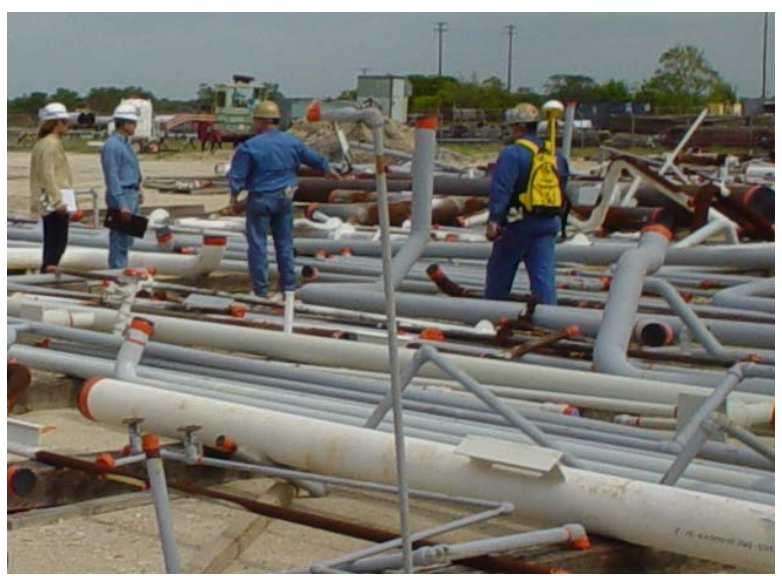

Figure 3. Crowded areas require sub-meter accuracy 


\subsection{Potential benefits and identified barriers}

The experience acquired during the field trial encouraged us to share some of the observations regarding the technical feasibility, limitations, and potential benefits of the GPS integration within field materials management, including:

(1) Merging GPS within traditional practices would only result in partial benefits, while re-engineering current locating processes around GPS has the potential to further improve schedule, reliability and productivity.

(2) Even though GPS technology automatically determined accurate materials' positions in lay down yards with thousands of stored components, the identification of pipe spools still relied on human data entry. Application of isometric drawings, barcodes, and RFIDs would further reduce the percentage of errors during the data collection process.

(3) The knowledge of the components' location in large lay down yards opens the possibility to predetermine routes and pickup sequences for tasks such as materials loading.

(4) Sub-meter accuracy is required when locating materials in crowded areas.

The research team is conducting more field tests to clearly measure and quantify the impact of GPS within materials locating processes, while enhancing the assessment for recommendations and identified barriers.

\section{Acknowledgments}

The authors of this paper would like to thank both FIATECH and the Smart Chips project team.

\section{REFERENCES}

[1] The Business Roundtable, "Modern management Systems”, Construction Industry Cost Effectiveness, Report A-6, 1982.

[2] Kini, U., "Materials Management: The Key to Successful Project Management", Journal of Management in Engineering, Vol. 15, pp. 30-34, 1999.

[3] U.S. Census Bureau, “1997 Economic Census”, http://www.census.gov/prod/ec97/97c23-is.pdf, 2004

[4] O’Brien, K., "Planning Has Merit”, Electrical Contractor, Vol. 54, 1989.

[5] Construction Industry Institute, "Costs and Benefits of Materials Management Systems”, CII, Research Summary 7-1, 1986.

[6] Bell, L.C., Stukhart, G., "Costs and Benefits of Materials Management Systems”, Journal of
Construction Engineering and Management, Vol. 113, pp. 222-234, 1987.

[7] Borcherding, J.D., Sebastian, S.J., "Major Factors Influencing Craft Productivity in Nuclear Power Plant Construction”, Transactions of the American Association of Cost Engineers, Paper I.1., 1980.

[8] Vorster, M. C., Lucko, G., "Construction Technology Needs Assessment Update”, CII, Research Report 173-11, 2002.

[9] Ibn-Homaid, N. T., “A Comparative Evaluation of Construction and Manufacturing Materials Management”, International Journal of Project Management, Vol. 20, pp. 263-270, 2002.

[10] Bell, L.C., Stukhart, G., “Attributes of Materials Management Systems", Journal of Construction Engineering and Management, Vol. 112, pp. 14-21, 1986.

[11] Jaselskis, E. J., Anderson, M. R., Jahren, C. T., Rodriguez, Y., Njos, S., "Radio-Frequency Identification Applications in Construction Industry”, Journal of Construction Engineering and Management, Vol. 121, pp. 189-196, 1995.

[12] Cheng, M. Y., Chen, J. C., "Integrating Barcode and GIS for Monitoring Construction Progress", Automation in Construction, Vol. 11, pp 23-33, 2002.

[13] Chen, Z., Li, H., Wong, C.T.C., “An Application of Bar-Code System for Reducing Construction Wastes", Automation in Construction, Vol. 11, pp 521-533, 2002

[14] Akinci, B., Patton, M., Ergen, E., "Utilizing Radio Frequency on Precast Concrete Components Supplier's Perspective”, International Symposium on Automation and Robotics in Construction, 19th (ISARC), Proceedings, pp. 381-386, Gaithersburg 2002.

[15] Saidi, K. S., Lytle, A. M., Stone, W. C., "Report of the NIST Workshop on Data Exchange Standards at the Construction Job Site”, International Symposium on Automation and Robotics in Construction, 20th (ISARC), Proceedings, pp. 617622, Eindhoven 2003.

[16] Stone, W. C., Cheok, G. S., Furlani, K. M., Gilsinn, D., “Object Identification Using Bar Codes on LADAR Intensity”, NIST, 2001. 